\title{
The Exploring Research on Principle of Bionics for the Preparation of Wood Composite Material
}

\author{
Er-De JIANG ${ }^{1, a}$, De-Hua LI ${ }^{2, b}$, Xiu-Rong LI ${ }^{3 c^{*}}$, \\ ${ }^{1}$ ShanDong Water Polytechnic, Rizhao Shandong 276826, P.R.CHINA; \\ ${ }^{2}$ Rizhao Polytechnic, Rizhao Shandong 276826, P.R.CHINA; \\ ${ }^{3}$ College of Forestry, Guangxi University, Nanning, Guangxi 530005 P.R.CHINA \\ ajiangerde18@126.com, ${ }^{b}$ Lidehua00@126.com, ${ }^{*}$ rongrong1994@163.com
}

\begin{abstract}
Keywords: Bionic Structure; Imitating the Natural; Wood Composite Materials; Super Hydrophobic
\end{abstract} TiO2 Coating

\begin{abstract}
The exploration and research have been further developed on Bionics principle in the felidof new wood composites preparation. Originally, the preparation ideas of gel-type wood composite material is based on utilizing the natural wood material which is formed during the long-term evolution of biological structure. This new-type multifunctional composite material synthesizesthe excellent characteristics of light-quality wood material and takes advantage of the structural characteristics of cellulose frame strengthen, whose purpose is to accelerate the exploitation of cellulose of the quick-growing trees, inferior wood and wood processing residues, and also to endow excellent function with the aerogel structure and lightweight wood for the new composite materials. Furthermore, the super hydrophobic surface of $\mathrm{TiO} 2$ coating whichis prepared on the material surface can make the material have the functions of Self-cleaning, environmental stability, organic pollutants and air purification.
\end{abstract}

\section{Preface}

Bionics is a newly-flourishing science, which is penetrated and combined by the biology, mathematics, and engineering science mutually. With the development of chemistry, material science, molecular biology, and the nanotechnology, bionics is developed toward the direction of micronano structure and micronano system, which has become an important branch of bionics research frontiers. Generally, biomimetic synthesis refers to a type of synthesis which makes use of the natural principle to guide the synthesis of special materials. Namely, inspired by nature creatures with special structure and function, it imitates or uses biological structure, function, and biochemical to apply to the design of materials with the aim to obtain the new material which is close to or exceeds the excellent properties of biological materials. Alternatively, it obtains the needed material making use of natural biosynthesis method [1]. Currently, the methods of utilizing Bionics principle in the exploration of preparing new wood composite material and the research of preparing raw materials can be briefly summarized as follows:(1)by means of preparing materials whose biological structure or configuration with creatures to replace natural materials such as biomimetic materials with hollow structure, bionic ion channels, imitating organism bones, etc[2 5].(2) to directly simulate unique functions of creatures to obtain the needed new materials, such as imitating lotus leaf super hydrophobic materials[2]. In this way, Gel-type wood composite material is just a kind of new prepared wood composites [3]. According to the principle of bionics preparation.

\section{Preparation of Gel-Type Wood Composite Materials}

The preparing process is as follows: place the oil bath pot in a magnetic stirrer, fix the flat bottom beaker in it, join the magnon, and conduct the dissolution experiment according to different dissolution conditions; add the weighed activation cellulose to the flat bottom beaker in [amim] $\mathrm{Cl}$, make the cellulose concentration reach to $5 \mathrm{wt} \%$, and implement magnetic stirring in $80^{\circ} \mathrm{C}$; The 
cellulose is gradually dissolved under oil bath heating and stirring condition. After the last added cellulose is totally dissolved, the next cellulose is added until the added cellulose is no longer dissolved [4][5] .

\section{The Structural Analysis of Gel-Type Wood Composites}

Wood is a kind of porous and limited expansion colloid formed natually, which is an organic complex composed with natural polymer. There are three types of Pores in the wood. The first is the inner cavity of the cells. The cells of different species vary in size, the widths of which vary from 50 $\mathrm{m}$ to $1500 \mathrm{~m}$; the second type is cell gap. The two types of pores are also known as permanent porosity. When the wood swells in obsorbing water and lapses in losing water, the sizes of pores does not change nearly; the third type is existed in the micropores of wood cell walls, also known as instant void. It will appear with the wood's wetting and disappear with the wood's drying. The three types of pores changes with different species, approximately varing from $47 \%$ to $83 \%$. After the test to the selected six light wood, it shows that the pore rate of ocharoma pyramidale is $89.78 \%$, the prepared gel type wood $82.12 \%$, which is lower than the Ocharoma pyramidale and is close to that of Erythrina arborescens (See Table 1).

Table 1 Basic physical quantities of six kinds of wood

\begin{tabular}{ccccc}
\hline Tree species & $\begin{array}{c}\text { Oven-dry } \\
\text { densityg/cm }\end{array}$ & $\begin{array}{c}\text { Air-dry } \\
\text { densityg/cm }\end{array}$ & $\begin{array}{c}\text { Equilibrium } \\
\text { moisture content \% }\end{array}$ & $\begin{array}{c}\text { Oven dry } \\
\text { porosity\% }\end{array}$ \\
\hline $\begin{array}{c}\text { Ocharoma } \\
\text { pyramidale }\end{array}$ & 0.157 & 0.166 & 7.72 & 89.78 \\
$\begin{array}{c}\text { Erythrina } \\
\text { arborescens } \\
\text { Ceiba }\end{array}$ & 0.302 & 0.315 & 8.20 & 80.38 \\
$\begin{array}{c}\text { Duabanga } \\
\text { grandiglora }\end{array}$ & 0.333 & 0.352 & 8.84 & 78.36 \\
$\begin{array}{c}\text { Trema } \\
\text { orientalis } \\
\text { Eoudia }\end{array}$ & 0.352 & 0.372 & 9.02 & 77.13 \\
rutaecarpa & 0.396 & 0.415 & 8.99 & 74.31 \\
\hline
\end{tabular}

For the fiber beam formed after the dissolution of cellulose, one part of it is acted as the supporting frame and another part of it forms the unclosed three-dimensional cross linked network. The inner gel-type wood is filled with microporous and mesoporous structure of the classification, which has stable chemical and physical properties. The large-scale pore size is within the range of $0.2 \mathrm{~mm}$. The pores range regularly with the structure of skeleton, surrounded by micron three-dimensional cross-linked structure, forming microfibril morphology (See Figure 1-b). In the electron microscope image a, the pit structure can be clearly observed, which is similar to the inside of the cell wall and can maintain the internal air circulation. The fiber beam inside the gel-type composite material becomes the main substance forming wood cell wall. As the skeleton material, it makes the whole wood stucture have a high tensile strength. 


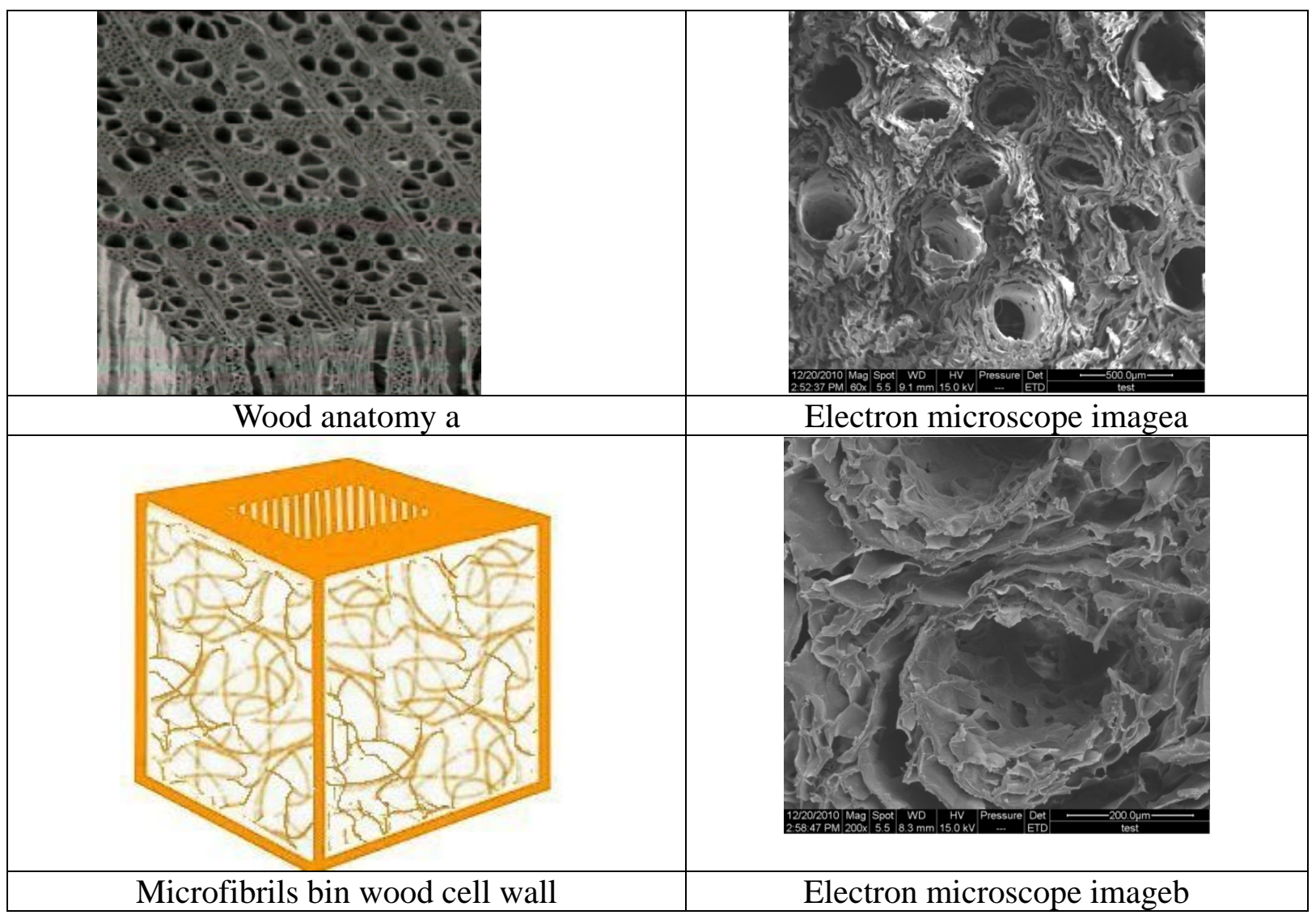

Fig. 1 Comparison of wood structure and gel type wood composites

\section{Preparation Mechanism and Process of Super Hydrophobic TiO2 Crystal Layer}

The research shows that self-cleaning ability on the surface of lotus leaf and the super hydrophobic attribute is up to the special surface (usually the surface whose contact angle is larger than $150^{\circ}$ is called super hydrophobic surface). The contact angle between the surface and water is about $160.4^{\circ} \pm 0.47^{\circ}$,the rolling angle of 1.90 degrees. The super hydrophobic attribute on the surface of super hydrophobic plant leaf is determined by both the epidermal hydrophobic wax crystal and rough surface microstructure. The super hydrophobic plant leaves have good waterproof and self-cleaning property. Inspired by the nature of super hydrophobic surface, we realize that the modification of hydrophilic gel type wood composite material surface into super hydrophobic surface materials will have broad application prospects in industrial and agricultural production as well as our daily lives, which has aroused extensive attention. Especially in the past ten years, the research of super hydrophobic surface is very active, both in the theoretical basis, structure construction technology, and applying aspects have made significant progress.

The situ composite of super hydrophobic TiO2 layer on the surface of gel-type wood composite material is just to imitate super hydrophobic structure principle on the lotus leaf surface, which puts hydrophilical aerogel gel-type wood on the surface of superhydrophobic inorganic nano to make it have the better environmental adaptability, selfcleaning properties, and durability with the aim to get a broad application prospect.

The loaded conditions of synthesizing $\mathrm{TiO} 2$ nanoparticles on the surface of gel-type wood composite materials are shown in Table 2. One representative preparation process is illustrated as follows: firstly, place the gel-type wood composite material into butyl titan ate and ethanol solution, sealing the reactor vessel. The temperature control conditions are shown in Table 2;

After the reaction kettle is conducted heating processing, the temperature of the reaction kettle is firstly reduced to the room temprature condition. Then the reaction kettle is opened and twelve sodium dodecyl sulfate solution with different $\mathrm{pH}$ value is added with the molar ratio of 9.1 * $10-4 \mathrm{~mol} / \mathrm{L}$. Next, the reaction kettle is resealed, and heated to $70^{\circ}$, holding the condion for 4 hours. 
The samples of the collected processed aerogeln gel-type wood material are heated for 24 hours in the condition of $45^{\circ} \mathrm{C}$. For necessary comparison, the wood samples without pretreatment were also needed to prepare. In order to meet the needs of $\mathrm{TiO} 2$ particles in the surface of the growth conditions, parts of samples will be dried with the method of stove-drying and samples are weighed. According to the technical requirements before and after reaction.

Table 2 Treatment conditions for water heating

\begin{tabular}{|l|l|l|l|l|l|}
\hline Samples & Temperature $\left({ }^{\circ} \mathrm{C}\right)$ & Time $(\mathrm{h})$ & $\mathrm{pH}$ & $\mathrm{m}(\mathrm{TBOT})(\mathrm{g})$ & $\% \mathrm{TiO}_{2}$ \\
\hline T1 & 70 & 1 & 6.5 & 5 & $11.2 \%$ \\
\hline T2 & 70 & 1 & 1.0 & 5 & $9.6 \%$ \\
\hline T3 & 70 & 4 & 6.5 & 5 & $17.4 \%$ \\
\hline T4 & 70 & 4 & 6.5 & 40 & $31.8 \%$ \\
\hline T5 & 70 & 4 & 1.0 & 5 & $14.6 \%$ \\
\hline T6 & 70 & 8 & 6.5 & 5 & $23.7 \%$ \\
\hline T7 & 70 & 8 & 1.0 & 5 & $18.7 \%$ \\
\hline T8 & 100 & 4 & 6.5 & 5 & $32.6 \%$ \\
\hline
\end{tabular}

\section{Performance Test and Analysis of 4 to Gel-Type Wood Composites}

The water contact angle test is conducted on the untreated experimental materials applying the contact angle tester. The test result is 52 degree, as shown in Figure 2, which shows hydrophilicity of the material. After the situ composite of super hydrophobic TiO2 layer of 220nm and $420 \mathrm{nmTiO} 2$ respectively on the surface of gel-type wood composite materials, the contact angle test results of gel-type wood composite materials are $124^{\circ}$ and $136^{\circ}$ respectively (See Figure 3a, b). The test results show that the contact angle on the surface of the material will increase with the size increase of specimen on the surface of $\mathrm{TiO} 2$ particles, showing strong hydrophobicity.

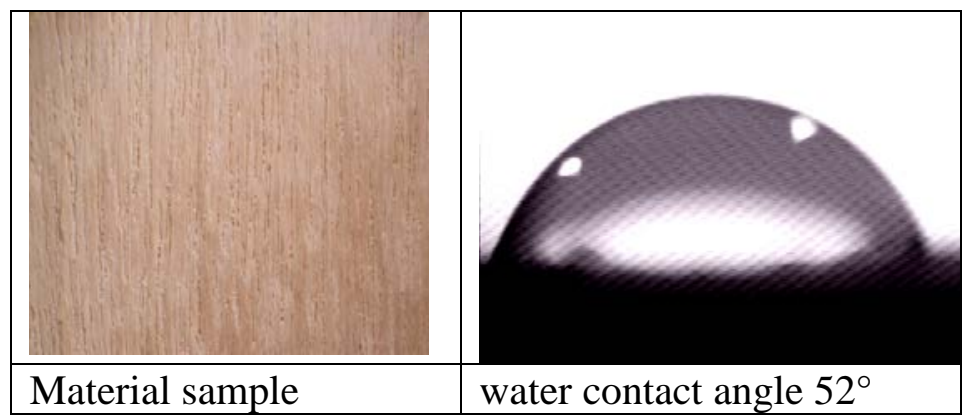

Fig.2 Light microscope image of blank wood and the magnification of contact Angle test

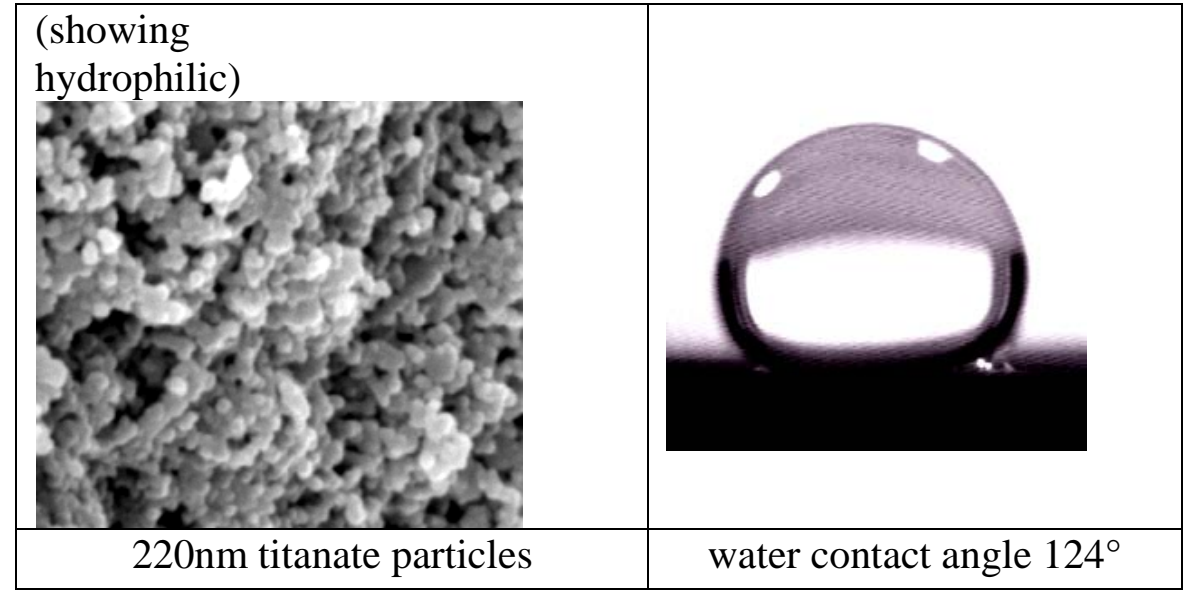

Fig.3 (a)SEM image of treated wood surface, at $70^{\circ}$ temperature( showing hydrophily) 


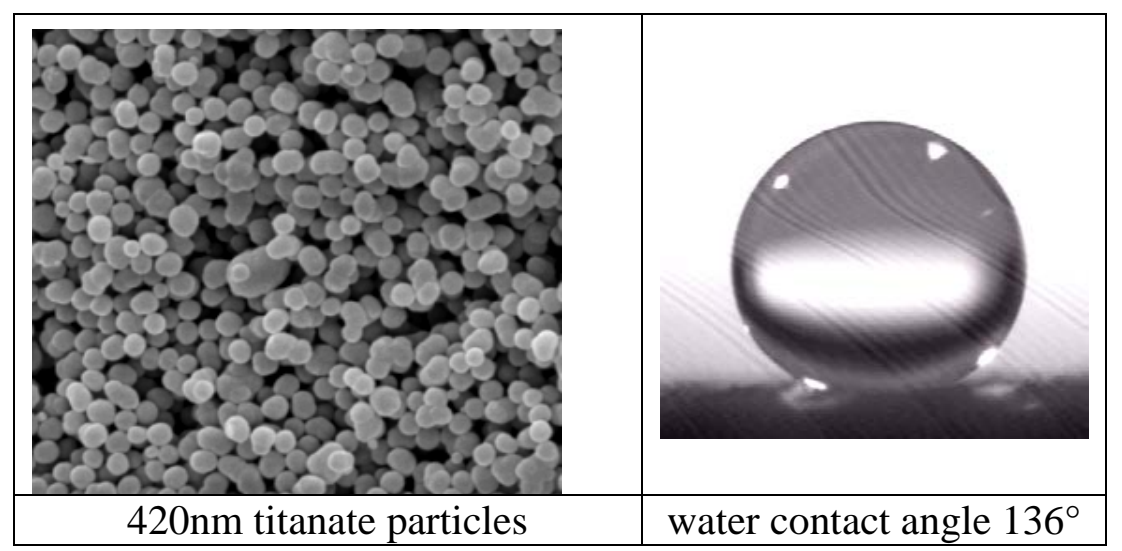

Fig.3 (b)SEM image of treated wood surface, at $70^{\circ}$ temperature( showing hydrophily)

\section{Conclusions}

(1) Based on the natural structural properties of balsa wood, this thesis put forward the preparation perception of gel-type wood composite basing on the wood main component and imitating wood cell structure and prepared a new wood-based material which owns the new environmental science nature and the special functions. This type of material is prepared and obtained through the selection of 1-propenyl imidazolium ionic liquids and supercritical drying process to fabricate. For the fiber beam formed after the dissolution of cellulose is acted as the supporting frame and forms the unclosed three-dimensional cross linked network, which owns similar microstructure with light wood as well as stable chemical and physical properties with the absolute dry density of $0.221 \mathrm{~g} /$ $\mathrm{cm} 3$ and the porosity of more than $87 \%$.

(2) The experiment is applied by contact angle measurement and SEM analysis. The results show that the TiO2 crystal layer in situ synthesis can effectively change the surface properties of aerogel type wood. The contact angle test values of the samples obtained through two typical process conditions are $124^{\circ}$ and $136^{\circ}$ respectively. The contact angle on the surface of the material will increase with the size increase of specimen on the surface of $\mathrm{TiO} 2$ particles, showing strong hydrophobicity. In this way, good self-cleaning properties, environmental stability and durability can be obtained.

Combining bionics science with materials science to carry out the research of bionic structure, function, and structure-function-integration material has important scientific significance. The bionic structure as well as its functional materials plays an important role in promoting and supporting function to the development of hi-tech, which has broad application prospects in aviation, aerospace, and national defense.

\section{Acknowledgements}

This work was financially supported by the project of domestic scholar funding for outstanding young teachers in Shandong Province. This work was also supported by the Guangxi University Research Foundation Project (XBZ130063).

\section{References}

[1] Diao she, Geng Zengchao. The research progress on the conversion and utilization of agricultural straw biomass [J]. Journal of Northwest Forestry University, 2010,25 (01): 157-161.

[2] Jian Li, Haipeng Yu, Qingfeng Sun, etc. Growth of TiO2 coating on wood surface using controlled hydrothermal method at low temperatures, Applied Surface Science, 2010, 256, 5046-5050.

[3] Xiurong Li, Dehua Li, Erde Jiang, etc. Research on the preparation of wood-based composite 
materialsusing wood processing residues [J], Applied Mechanics and Materials, 2013(357-360 ):1254-1258.

[4]Xiurong Li, Bingzhao Liang, Dehua Li, etc. On the Application of Green Ionic Liquids in the Preparation Process of the Gel-type Wood Composites Materials, Applied Mechanics and Materials Vols. 357-360 (2013) pp 1039-1044.

[5] Xiurong Li, Yunlin Fu, Tao Jiang, etc. The Preparation and Research of the Aerogel-type Wood Composite Material, Advanced Materials Research Vols. 634-638 (2013) pp 1124-1128

[6]Y. F. Li, J. Li, Y. X. Liu, etc. Thermoforming of polymer from monomers in wood porous structure and characterization for wood-polymer composite. Materials Research Innovations, 2011, 15(S1): 446-449.

[8] Yongfeng Li, Xiaoying Dong, Yixing Liu, etc. Improvement of decay resistance of wood via combination treatment on wood cell wall: Swell-bonding with maleic anhydride and graft copolymerization with glycidyl methacrylate and methyl methacrylate. International Biodeterioration \& Biodegradation, 2011, 65 (7): 1087-1094.

[9] Yongfeng Li, Qinglin Wu, Jian Li, etc. Improvement of dimensional stability of wood via combination treatment: Swelling with maleic anhydride and grafting with glycidyl methacrylate and methyl methacrylate. Holzforschung, 2012, 66: 59-66.

[10]Yongfeng Li, Xiaoying Dong, Zeguang Lu, etc. Effect of polymer in situ synthesized from methyl methacrylate and styrene on the morphology, thermal behavior and durability of wood. Journal of Applied Polymer Science, 2013, 128(1): 13-20.

[11]Tao Jiang,Xiurong Li, Yanjun Xie, etc. Effects of Microwave Pretreatment on the Permeability of Eucalyptus grandis $\times$ Eucalyptus urophylla [J]. Journal of Northwest Forestry University, 2013, 28(01): 174- 177.

[12] Li Bo, Tao Gongsheng, Yin Feng Xie, The influence of Nano TiO2 on diurnal changes of Indocalamus barbatus photosynthesis [J]. Northwest Forestry College Journal, 2012,27 (01): 35-39. 